\title{
Era uma vez... a revolução: a trajetória de Sergio Leone nas páginas da Cahiers du Cinéma
}

Rodrigo Carreiro'

1. Professor do Programa de Pós-Graduação em Comunicação (PPCCOM) da Universidade Federal de Pernambuco (UFPE) e coordenador do Bacharelado em Cinema da mesma instituição. Possui doutorado (201 I) e mestrado (2003) em Comunicação pela UFPE, e é graduado em Jornalismo pela Universidade Católica de Pernambuco (1994). Dedica-se a pesquisas nas areas de Teoria do Cinema, História do Cinema e Estudos do Som. 


\section{Resumo}

A maior parte dos críticos cinematográficos dos anos 1960-70 minimizou ou desprezou o valor estético dos filmes vinculados ao ciclo de spaghetti westerns, produzidos naquela época no eixo Itália-Espanha. No entanto, Sergio Leone, principal cineasta a emergir do ciclo, rompeu essa barreira ao longo dos anos e se tornou um diretor respeitado pela crítica. Mapear como ocorreu essa trajetória e avaliar os motivos que levaram a essa mudança no estatuto de valor associado ao trabalho de Leone são os objetivos deste artigo, que toma como estudo de caso a coleção de todos os textos sobre os filmes do diretor publicados, a partir de 1964, na revista Cahiers du Cinéma, referência obrigatória na crítica cinematográfica internacional.

\section{Palavras-chave}

história do cinema, crítica de cinema, western

\section{Abstract}

Most 1960s and 1970s film critics minimized or dismissed the aesthetic value of the films linked to the spaghetti Western cycle, produced at that time in the Italy-Spain axis. However, Sergio Leone, aleading film maker to emerge from the cycle, broke this barrier and became an influential director over the years. This article aims tomaphow this trajectory occurred and to assess the reasons why this change took place in the statute of value linked to the work of Leone, takingas a case study a collection of all the texts published in the journal Cahiers du Cinema - an obligatory reference in international film criticism -, since 1964, about the director's films.

\section{Keywords}

film history, film criticism, Western 
temáticas

livres

Quando Sergio Leone morreu, no dia 30 de abril de 1989, havia se tornado um cineasta influente e respeitado. Mas nem sempre foi assim. Durante a maior parte da carreira, nos anos 1960 e 1970, enquanto filmava westerns de baixo orçamento nos desertos de Espanha e Itália, Leone encarnou um estereótipo muito comum aos artistas de origem popular: era adorado pelo público e desprezado por críticos e pesquisadores.

O biógrafo Christopher Frayling resume a recepção crítica ao trabalho de Leone, naquelas décadas, com uma frase: "Quando os westerns de Leone começaram a ser lançados no exterior, foram invariavelmente despedaçados pelos críticos" (FRAYLING, 1981: 121). Não é retórica. As reações ao trabalho de Leone eram, em alguns casos, expressas com sarcasmo e agressividade. No programa de TV Today Show, exibido nos Estados Unidos pela rede NBC, Judith Crist resumiu o sentimento de muitos críticos, ao analisar Por um punhado de dólares (Sergio Leone, 1964) dessa forma: “Essa porcaria só serve para espectadores com pendor por lixo sangrento" (CRIST, 1974: 211).

Hoje em dia, críticos de todo o mundo olham para esse mesmo filme de modo muito diferente. O spaghetti western alcançou uma notoriedade que seus fãs não podiam imaginar. É possível citar exemplos institucionais que confirmam essa impressão. Em agosto de 2004, o Museum of the American West, um dos mais importantes espaços de preservação da memória da colonização do oeste daquele país, dedicou uma mostra aos filmes de Leone, expondo peças de figurino, cenário e cartazes das produções dele; um evento desse tipo seria impensável nos anos 1970, quando críticos consideravam o western feito na Itália como uma espécie de insulto à memória histórica do passado norte-americano. 
Leone, como principal diretor vinculado ao ciclo de spaghetti westerns, foi o principal beneficiado por essa revalorização crítica do gênero. Mas como ocorreu esse processo? De que maneira o discurso da crítica mudou? O que impulsionou essa alteração? Ela foi abrupta ou gradual? É possível reconhecêla quando se olham em retrospectiva os textos escritos pelos críticos dos anos 1960 e 1970? Quais contextos a impulsionaram?

O objetivo deste artigo é responder a essas perguntas, mapeando a recepção aos filmes de Leone ao longo das décadas de 1960-70-80 (o período em que ele estava vivo). Usaremos, como estudo de caso, o conjunto de críticas publicadas na revista Cahiers du Cinéma: nove resenhas divulgadas entre maio de 1965 e maio de 1972, e mais um dossiê de 16 páginas incluído na edição 359 (maio de 1984).

A escolha da Cahiers baseia-se no contexto da cinefilia do período analisado, quando a revista era a principal referência da crítica cinematográfica no mundo. Por fatores que escapam aos objetivos do artigo, a importância da publicação francesa diminuiu desde então, mas, pelo menos até o advento da internet comercial em larga escala, em meados dos anos 1990, a Cahiers influenciava decisivamente na formação do gosto dos críticos e cinéfilos, bem como na atribuição de valor a produtos audiovisuais.

\section{Fortuna crítica}

No período mais prolífico da carreira de Leone, que cobriu a segunda metade dos anos 1960 e a primeira dos anos 1970, a Cahiers du Cinéma dedicou nove textos à a nálise de cinco westerns dirigidos por ele. Esses textos foram divulgados durante um intervalo de exatos sete anos - de maio de 1965 a maio de 1972. Uma mera olhada nesse material demonstra a atenção crescente dedicada pelos redatores aos filmes, já que o espaço editorial reservado à impressão dessas críticas aumentou a cada novo texto. 
ano I número I

temáticas

livres

A primeira resenha, publicada no número 166, em seguida ao lançamento europeu de Por uns dólares a mais, sequer merece ser chamada de crítica, pois consiste de um único parágrafo que contém a ficha técnica do filme e uma sentença solitária e desinteressada, que não contém nenhum tipo de análise, resumindo-se a decretar que se trata de uma "tentativa de repetir o sucesso de Por um punhado de dólares" (MARDORE, 1965: 73). Nas entrelinhas, o texto sugere que os objetivos de Leone eram puramente comerciais. É preciso observar, também, que o primeiro western dele, feito um ano antes, havia sido ignorado pela Cahiers. A ausência diz muito a respeito da importância que os críticos atribuíam a Leone.

O sucesso de Por uns dólares a mais levou à necessidade de que a Cahiers criticasse efetivamente o filme. Assim, o número 176 (março de 1966) trouxe outro texto sobre ele. O artigo não fala apenas do cinema de Leone; reúne quatro longas-metragens italianos e analisa-os, um de cada vez, sob o pretexto de sintetizar a produção recente do país. Um parágrafo é dedicado ao filme de Leone, que o crítico Jacques Bontemps considera "menos ruim" do que o anterior. Bontemps desvaloriza o trabalho de direção, considerando como defeitos alguns recursos de estilo que, anos depois, viriam a ser julgados positivamente, de forma invertida, por outros críticos: "Leone não tem critério nas composições visuais, os atores são histriônicos, a ação física é ampliada ao máximo e os assassinatos numerosos acabam reduzidos a signos sem qualquer carga afetiva". Por uns dólares a mais não passa de um "buquê de flores artificiais" (BONTEMPS, 1966a: 12).

A crítica é curta, mas significativa. Bontemps classifica Leone como diretor “barroco" (é a primeira de três menções feitas na Cahiers ao estilo artístico que floresceu no século XVII, relacionando-o ao trabalho de Leone), seguindo um clichê da época - Georges Sadoul havia escrito pouco antes, em seu Dicionário de cineastas, que Leone fazia jus à "tradição barroca italiana" (SADOUL, 1979: 184). No texto da Cahiers, essa classificação aparece associada à metáfora 
das flores artificiais e sugere que no filme há um gosto pelo exagero, um predomínio da forma em relação ao conteúdo. Contraditoriamente, esse suposto barroquismo assinala o único aspecto digno do (pouco) interesse que Bontemps encontra no filme:

O excesso [é] a única possibilidade de um western europeu existir sem ser insuportável, se fazendo exercício de estilo barroco e decadente num gênero que só está presente pela ausência nostalgicamente sentida: o western. (BONTEMPS, 1966a: 12)

A observação a respeito da ausência de elementos do repertório do gênero alinha-se à convicção, ecoada por muitos outros críticos, de que um western só poderia ser considerado bom se viesse dos Estados Unidos e, mais do que isso, se respeitasse o repertório de convenções estabelecido pelos cineastas daquele país. Afinal de contas, o western lidava com a identidade cultural e com a História (com maiúscula) dos EUA.

Para não deixar passar em branco o primeiro western de Leone, o número seguinte da revista ( $\mathrm{n}^{\circ}$ 177, abril de 1966) retornou a Por um punhado de dólares, em crítica de um parágrafo, acompanhada de ficha técnica. O texto do mesmo Jacques Bontemps chama a atenção, sobretudo, por deslocar o diretor do restante do ciclo dos spaghetti westerns, situando-o numa posição destacada dentro do panorama de produção popular na Europa. Em seguida, o crítico recontextualiza o filme negativamente, calcado na ideia de uma representação espetacular da violência:

Claramente superior a todos os demais westerns europeus, o que não significa, de jeito nenhum, que tenha o menor interesse, já que se há alguém convencido da pretensão da empreitada é o próprio Sergio Leone. Um desencanto total, portanto, e uma violência exacerbada demais para ser eficaz. (BONTEMPS, 1966b: 81)

No número 184 (novembro de 1965), Patrick Brion retornou pela terceira vez a Por uns dólares a mais, reafirmando alguns dos argumentos 
ano I número |

temáticas

livres

de Bontemps, como a suposta qualidade superior de Leone em relação aos demais cineastas do spaghetti western ("sua austeridade sobressai ao resto dos subprodutos do western hispano-italiano"). A representação gráfica da violência incomodava ("os assassinatos se sucedem invariavelmente, sem qualquer motivação psicológica") e era responsável, na visão de Brion, pela suposta "degenerescência do gênero".

Nos dois últimos textos, é importante perceber que os críticos deixam escapar julgamentos favoráveis, mas sempre dentro do contexto isolado do spaghetti western, jamais em relação ao western estadunidense. Ironicamente, nos dois casos, os elogios têm relação direta com o que Brion chama de "floreios barrocos"2 e que podemos associar às preocupações formais: as composições pictóricas recessivas, com diferentes figuras espalhadas em diferentes camadas de profundidade da tela; os close-ups extremos; o desenho sonoro lacônico, de poucas palavras e muitos ruídos (vento, galopes, tiros, chicotadas) e principalmente o caráter irônico, presente no alusionismo, e que podemos associar à influência das tradições italianas da commedia dell'arte. Ou seja, os mesmos recursos que Jacques Bontemps havia criticado de forma enfática no primeiro texto dedicado pela revista a Leone:

Por outro lado - e a eficácia certeira do filme tem aí suas raízes - a violência exacerbada chega ao limite do suportável, apesar de alguns floreios barrocos que introduzem o necessário recuo humorístico. (BRION, 1966: 73).

Ainda que a crítica de Patrick Brion esteja longe de ser positiva, é possível notar que o eixo principal do texto está no mesmo fenômeno estilístico notado por Jacques Bontemps - a tendência de Leone à revisão intensificada de certos recursos formais, que ambos associam a um suposto exibicionismo "barroco". Brion usa o mesmo vocabulário para se referir a esse fenômeno, mas elabora um pouco mais a gênese de uma ideia já presente em Bontemps: a noção de 
releitura crítica do gênero, de revisão dos esquemas ${ }^{3}$ através da releitura de certos elementos de repertório de códigos do gênero.

Depois de demorar a publicar as críticas dos dois primeiros westerns de Leone, a Cahiers du Cinéma foi rápida em analisar Três homens em conflito. O longa-metragem foi lançado na França em 8 de março de 1968; o texto escrito por Sylvie Pierre apareceu no número 200 da revista, no mês seguinte. A rapidez do processo de edição era um sinal claro de que a carreira de Leone agora estava sendo acompanhada com mais atenção pela revista. O texto fez parte da seção "Notas críticas", editada no final da revista, que agrupava fichas técnicas e comentários curtos sobre lançamentos recentes. A crítica ocupou dois terços de página - o maior espaço editorial dedicado até então a um filme de Leone na Cahiers.

É uma crítica ambígua, que permite leituras positivas e negativas. Sylvie Pierre obser va que Leone levava a cabo, ao contar a odisseia dos três vagabundos por dentro de um território em guerra - que, ela afirma, “não é nada além de um olhar europeu sobre a guerra de trincheiras de 1914, não se pretendendo de jeito nenhum um panfleto antimilitarista" - atrás de um tesouro enterrado, "uma operação apaixonante" (PIERRE, 1968: 124).

Pierre registra procedimentos estilísticos recorrentes dentro do filme, como a tendência de Leone para os jogos de percepção imagética, com a entrada de personagens dentro do espaço fílmico sem serem percebidos por outros personagens que já se encontram dentro dele. Também destaca a verossimilhança dos acessórios utilizados por Leone, evocando o realismo grotesco dos cenários e figurinos.

3. Esquemas são conjuntos de normas de estilo disponíveis aos artistas de determinada época para resolver problemas de representação (GOMBRICH, 2007). Essas técnicas se firmam aos poucos, no repertório dos artistas, quando se mostram bem-sucedidas. Elas podem ser replicadas, revisadas, sintetizadas ou rejeitadas pelos artistas. Os esquemas funcionam mais ou menos como sistemas de códigos (ou seja, regras narrativas e estilísticas) que produzem significados a partir da manipulação de significantes. Esquemas são flexíveis o suficiente para que cada artista, dentro dos contextos de produção em que opera, os modifique ou adapte em variados graus de ênfase. 
No entanto, sua observação mais interessante diz respeito ao perfil amoral

ano I número 1

temáticas

livres do trio de protagonistas. Embora num primeiro momento critique Leone por desrespeitar a "função clássica do maniqueísmo do western" (mais uma vez, o processo de revisão crítica do esquema dominante de representação, procedimento natural para Leone, era compreendido como algo negativo), Pierre aprofunda sua análise, chegando à conclusão de que a brincadeira irônica com os rótulos de "bom", "mau" e "feio" (presentes no título original) consiste no maior charme do filme:

É original, aqui, a complexidade da perturbação trazida ao esquema maniqueísta do western. De Lee Van Cleef (o bandido violento que mata crianças) a Clint Eastwood (o homem bom de moralidade duvidosa), passando por Eli Wallach (o vagabundo simpático), existe uma degradação no uso desse recurso. Mas a astúcia do filme, sua mais bela intenção, consiste em uma operação de dissimetria da ironia aplicada às etiquetas dos personagens. (...) Nem o bom, nem o mau trazem provas de uma maldade absoluta. Um fecha os olhos dos moribundos com gentileza; o outro rouba os relógios deles com cinismo. Finalmente, se é o mau o único eliminado dos três, não é esse fato que evoca a euforia do puro espetáculo. É preciso que os dois sobreviventes se emancipem da ficção westerniana e se tornem dois indivíduos quaisquer num tempo de guerra, e que a carga de ouro de que tomam posse os afaste da aventura. (PIERRE, 1968: 124)

Apesar de o texto de Sylvie Pierre ser o primeiro a analisar mais detidamente recursos de estilo, chamam a atenção os comentários ambíguos sobre o processo de revisão dos esquemas do western. Além disso, em nenhum lugar existe menção ao pertencimento do filme ao ciclo popular italiano, que no ano de 1968 passava pelo momento mais numeroso e criativo de sua trajetória, com 83 filmes produzidos em 12 meses (WEISSER, 1992). Para elogiar Leone, Pierre preferiu destacá-lo do ciclo.

Pois é exatamente o contrário disso que se pode ler na sexta crítica sobre Leone publicada na Cahiers. A pretexto de comentar Era uma vez no Oeste, Serge Daney escreveu o texto mais significativo de todos os que se pode ler a respeito de Leone na revista. A resenha foi publicada no número 216 (outubro 
de 1969), constituindo o primeiro de dois textos que a revista imprimiu sobre o longa-metragem - Sylvie Pierre escreveria uma crítica mais longa, dois números depois, que essencialmente reelaborava argumentos parecidos, só que procurando destacar um pouco mais os aspectos de estilo.

A crítica de Daney é o texto que resolve melhor as ambiguidades sentidas nas resenhas da revista. Os críticos estavam sempre prontos a decretar o spaghetti western como intrinsecamente inferior ao western estadunidense, embora às vezes conseguissem enxergar elementos dignos de interesse no trabalho de Leone. A questão é que, até o texto de Daney, nenhum crítico havia explicado claramente o que seria esse algo interessante. Daney foi o primeiro a explicitá-lo: era o caráter de releitura crítica que Leone oferecia ao repertório de convenções do western tradicional, o esforço para elaborar uma variação criativa do esquema narrativo dominante do gênero, dominada pela irreverência, pela ironia e pelo humor negro. Só que Daney não comentou esse esforço a partir de uma análise estilística. Sua abordagem foi condizente com a fase maoísta/esquerdista que a Cahiers vivia na época.

Daney pouco se demorou na discussão sobre o filme em si ("marca o apogeu e talvez o colapso do ciclo", afirmou, em uma sentença que se revelaria quase premonitória, pelo menos a respeito de Leone), deixando-o de lado para se concentrar em defender a suposta agenda política do spaghetti western, articulando-a com o processo de releitura crítica do gênero, através de uma operação contínua de desconstrução do repertório de convenções:

\footnotetext{
Eles [os filmes de Sergio Leone] constituem a primeira tentativa, embora pouco consequente, de cinema crítico, ou seja, não mais em confronto direto com a realidade (mesmo que às vezes o recurso à verdade histórica que Leone conhece bem - tenha um valor estratégico), mas com um gênero, uma tradição cinematográfica, a única que conheceu uma difusão mundial: o western. Não é pouca coisa. (DANEY, 1969: 64)
}

O texto de Daney é paradigmático, antecipando o resgate posterior que se faria do cinema de Leone. Sem negar em nenhum instante o caráter popular 
ano I número 1

temáticas

livres

- inclusive no modo industrial de produção em série - dos spaghetti westerns, Daney critica os rumos que o western americano havia tomado na década de 1950, com uma tendência supostamente excessiva de psicologizar os personagens ("senso crítico, mas não cinema crítico", diz, avançando um argumento que já podia ser encontrado nos escritos de André Bazin sobre o western), e avaliza um cinema que lhe parecia crítico do próprio cinema. Para ele, uma poética cinematográfica que pusesse em xeque o moralismo exacerbado do gênero estadunidense só poderia ser elaborada fora de Hollywood.

E por que essa crítica haveria de florescer justo na Itália? Para Daney, a Itália era o lugar perfeito para o surgimento de um cinema popular crítico, um cinema que encapsulasse um caráter de resistência cultural e ideológica ao avanço cultural dos Estados Unidos. Afinal, o país europeu era um dos únicos no mundo a ter uma indústria de cinema popular, comparável aos EUA em números e estatísticas de bilheteria. As "origens vis e baixamente comerciais" (DANEY, 1969: 64) do ciclo italiano são, para ele, o aspecto mais positivo do spaghetti western.

A expressão entre aspas talvez seja o trecho mais significativo do texto de Daney. Ela denota claramente a linha de raciocínio que seria seguida por praticamente todos os críticos ao longo do processo de revalorização da obra de Leone nos anos 1970: a importância do spaghetti western não estava nos recursos de estilo, nem mesmo na fruição estética que os filmes proporcionavam. O ciclo popular italiano era importante na medida em que representava uma tentativa crítica de resistência cultural ao domínio estadunidense, desconstruindo-o de dentro para fora.

Ou seja, somente ao conservar o caráter de massa, de produto audiovisual oriundo de uma linha de montagem, o gênero italiano poderia realizar com propriedade o seu "eufórico trabalho de desconstrução", desmistificando todo um conjunto de convenções estabelecidas pela outra indústria do cinema: 


\begin{abstract}
Admitamos que em alguns países onde o cinema constitui uma indústria robusta, o cinema B delimita uma espécie de lumpencinema (cinema do lumpemproletariado), bom de qualquer modo para fazer a máquina girar, amado de forma esnobe e contraditória (em uma espécie de cinefilia "operária") não podendo aspirar à qualidade, nem mesmo à consciência clara dos elementos (temas, situações) que ele ilustra porque esta (a consciência) é reservada aos filmes de qualidade: digamos, mais para [Fred] Zinnemann que para [Alan] Dwan. (DANEY, 1969: 64)
\end{abstract}

Essa passagem reforça o argumento central do texto. Centrando a argumentação na primeira vertente da poética do cinema, Daney sugere que o spaghetti western não poderia aspirar à qualidade do western estadunidense, por ser uma cópia; ou seja, apesar de valorizar o ciclo, o coloca num patamar inferior ao ocupado por filmes de "qualidade". Em outras palavras, os filmes de Leone são bons na medida em que incitam à resistência cultural, mas, de um ponto de vista estético, não têm nada de novo a oferecer.

Apesar de tudo isso, ele elogia a narrativa do filme por eliminar o moralismo puritano do gênero (isto é, valoriza indiretamente o perfil do herói mais amoral). Sua leitura, obviamente, é compatível com a orientação ideológica de esquerda da Cahiers daqueles tempos. A revista tinha motivos políticos para reverenciar um cinema popular que propagava ideologias de esquerda, como era o caso do spaghetti western.

Mas, uma vez estabelecidos os contextos cultural e político em que se localiza a obra de Leone, Daney parte para analisar a utilização formal dos esquemas de representação revisados pelos diretores do spaghetti western. E afirma como característica mais importante deste procedimento o uso do pastiche como uma forma de explicitação da cinefilia, do conhecimento e da paixão por filmes. Tal uso não se dá apenas por uma questão de sensibilidade estética exagerada (embora esse argumento também esteja lá), mas também por uma estratégia crítica: 
ano I número |

temáticas

livres retórica habitual do western, em fazer do excesso de oferta o equivalente de uma negação. Em relação a isso, seria interessante mostrar como ao western convencional (...) Leone opõe uma sequência ininterrupta de tempos fortes que se anulam reciprocamente: ao máximo de intensidade corresponde um mínimo de sentido. (DANEY, 1969: 64)

Esse trecho é significativo. Daney enxerga-o como sintoma de procedimentos narrativos e estilísticos em direção a uma poética da intensificação. Ele está falando dos "floreios barrocos" a que outros críticos se referiram, atribuindo a eles um lado positivo (traziam consigo uma postura crítica) e outro negativo (provocavam desequilíbrio entre forma e conteúdo, com ênfase no primeiro item). Quando se refere a uma "sequência ininterrupta de tempos fortes", e obviamente sem usar o termo (que só seria criado décadas depois), Daney está se referindo à poética da continuidade intensificada (BORDWELL, 2006). ${ }^{4}$ No final do texto, ele retoma o raciocínio desenvolvido no início; reconhece que quase não tratou do filme, mas se coloca na contramão da corrente principal de críticos que não enxergavam valor na obra de Leone, observando que sua prática intensificada em estilo e narrativa nada tinha de gratuita, e que era preciso dedicar mais atenção aos filmes dele (algo que o próprio Daney, sintomaticamente, não faz):

\footnotetext{
Interessante notar como, neste cinema, se dá a escolha dos meios (chamada de gratuita por toda uma tropa de bem-pensantes), a construção da beleza (dos atores e paisagens), da justeza de tal ou qual estilo de narração (elipse ou tempos longos). (...) Quanto a Leone, de quem pouco se tratou aqui, é igualmente possível empreender a decifração de uma obra superabundante, com muitos elementos, em tiques retóricos. (DANEY, 1969: 64)
}

A análise das críticas subsequentes publicadas na Cahiers sobre filmes de Leone demonstra que o texto de Daney - não por acaso, um dos redatores mais influentes da revista na época - foi um marco fundamental na recepção crítica

4. Conjunto de procedimentos técnicos e estilísticos centrado na representação cada vez mais intensa da narrativa, a fim de proporcionar ao espectador uma experiência de imersão mais visceral na diegese (BORDWELL, 2006: 119). 
aos filmes do cineasta italiano. Mesmo sem ter dito explicitamente, Daney havia sinalizado (à comunidade cinéfila e, evidentemente, aos outros críticos da revista) que havia talento e originalidade no trabalho de Leone, e que este deveria ser levado mais a sério.

Desse momento em diante, percebe-se o surgimento de um padrão favorável na recepção dos críticos da Cahiers du Cinéma. Esse contexto fica evidente já a partir do destaque editorial dado à crítica de Sylvie Pierre sobre o mesmo filme, publicada no número 218 (março de 1970). O texto ocupa três páginas da revista; pela primeira vez, um longa-metragem de Leone era analisado fora da seção "Notas críticas", que se ocupava exclusivamente de lançamentos. A política editorial da publicação já o considerava um diretor digno de receber atenção, para além dos registros circunstanciais em épocas de lançamento de filmes.

Nesse sentido, convém observar que a ampliação do destaque editorial oferecido a Leone ocorreu justamente no momento em que mudou o contexto de produção dos seus filmes, com sua associação aos grandes estúdios estadunidenses de maneira mais direta. Sabemos que, embora ainda filmado na Espanha, Era uma vez no Oeste teve orçamento generoso, fugindo drasticamente dos limites e precondições impostos pelo modo de produção de Cinecittà. Eis, então, um paradoxo: elogiado por Daney por exercer um cinema popular de resistência contracultural, Leone ganhava espaço na revista exatamente no momento em que recorria ao dinheiro estadunidense para filmar com mais ostentação.

A abordagem de Sylvie Pierre ao filme de Leone é bastante distinta do texto escrito por ela dois anos antes, a respeito de Três homens em conflito. A nova crítica não apenas cita diretamente o texto paradigmático de Daney, mas procura desenvolver e aprofundar aspectos do raciocínio dele. Ela se concentra na agenda política supostamente defendida pelo filme (ou seja, investe na 
ano I número |

temáticas

livres mesma leitura ideológica que Daney havia feito), abrindo também espaço para algumas observações a respeito das práticas estilísticas e narrativas de Leone. Antes de falar qualquer coisa sobre o filme, Pierre desenha uma longa argumentação a respeito das conexões culturais entre o western americano e sua contraparte italiana:

O western não é nada além de um traço da ideologia sobre a história norteamericana, aquela inventando esta, pelo viés da mitologia, e de uma espécie de justificativa moral. Trata-se de justificar a história imperial dos Estados Unidos. (PIERRE, 1970: 53)

A partir daí, colocando-se na contramão de um dos argumentos mais citados pelos detratores do spaghetti western, Sylvie Pierre refuta a acusação de falta de autenticidade histórica dos filmes do ciclo, afirmando que essa acusação "não faz nenhum sentido", porque:

(...) não foram importados [dos westerns estadunidenses], evidentemente, nem a ideologia, nem a história, mas o produto acabado desse conjunto: a retórica. Ou seja, uma rede complexa de personagens, temas, situações, acessórios, cenários, roupas, que consiste apenas de variações combinatórias desses elementos, regidas por um código cuja necessidade permanece ininteligível. Sem dúvida, não é possível fazer esse empréstimo de outra forma que não seja do exterior (...). Leone, e com ele todo o western italiano, tomam emprestada a retórica ao western americano, mas fazem isso ao desenraizar a comodidade de um sistema já completamente constituído de figuras que, não tendo mais que se justificar em sua relação com o real, podem funcionar livremente, isto é, de modo gratuito. O empréstimo não é pequeno; ele é feito através de nada menos do que uma concessão, uma espécie de salto para fora da história. (PIERRE, 1970: 54)

Quando se refere à retórica, ela faz questão de definir o conceito: tratase do conjunto de recursos de estilo que compõem os esquemas do western americano. Nesse ponto, Pierre ignora o processo de revisão crítica de esquemas levado a cabo por Leone, sugerindo que os filmes não passam de "variações combinatórias" desses recursos.

Depois, num longo trecho que ocupa quase metade da crítica, ela se volta para o filme, observando a preocupação com a acuidade histórica e citando como 
exemplo a reconstituição minuciosa da cidade em construção, das estações de trem e dos saloons. Ela circunscreve um traço estilístico (a preocupação com a descrição histórica exata) que se tornaria, à frente, recurso importante da poética da continuidade intensificada, e busca uma justificativa de ordem sociocultural para o estabelecimento desse recurso:

Compreende-se muito claramente por que os westerns míticos de Cecil B. de Mille, Ford ou Mann não tinham que se preocupar em ser documentários, sendo eles mesmos documentos - documentos ideológicos americanos, imagens de um povo se olhando no espelho. O western de Leone, embora fantasioso, tende paradoxalmente à exatidão. Porque ele não se inventa de uma ciência difusa; é preciso que ele nasça de certo saber, que só será arqueológico sendo monumental. (PIERRE, 1970: 54)

Então, Pierre segue o raciocínio, insistindo na importância da ostentação formal - o "barroquismo" - dentro da obra de Leone. Ela sugere que há no filme uma tendência flagrante à ostentação estilística, à sobreposição da forma ao conteúdo:

\begin{abstract}
A história, em Leone, é apenas um espaço totalmente distinto da ficção, diante do qual a ficção morre e se exibe como um rabo de pavão, cheio de esplendores e vaidades. (...) Era uma vez no Oeste é, antes de tudo, uma obraprima de retórica. (PIERRE, 1970: 54)
\end{abstract}

Na argumentação, Sylvie Pierre cerca o filme sem mergulhar nele. O cerne da análise está na leitura ideológica do trabalho de Leone - uma leitura claramente devedora a Daney. Antes de encerrar o texto, Pierre ainda nota o uso abundante do alusionismo dentro da trama do filme, antecipando em muitos anos a definição que Noël Carroll (1998) faria do conceito - uma narrativa em camadas sobrepostas, em que o público amplo entende a trama e um grupo menor, formado por cinéfilos, recebe piscadelas para um gozo estético privilegiado:

Tudo é permitido, desde que a cada instante o cinema funcione e se veja funcionar. O resultado é de um narcisismo cinematográfico evidente. Um cinema que só remete a ele mesmo e a suas próprias mitologias. (...) O jogo duplo que poderia parecer no início duvidoso, entre a eficácia e 
ano I número |

temáticas

livres a contemplação, tem de um lado o cinismo do saber fazer e a política comercial que assegura o grande público; e do outro, o fato de que pisca o olho para os intelectuais, com todos os êxtases estéticos permitidos. (PIERRE, 1970, p. 55).

A leitura marxista de Pierre a leva a julgar como negativo o recurso do alusionismo (que até então, note-se, não havia sido citado por nenhum outro crítico da Cahiers); no momento em que Leone "pisca o olho para os intelectuais", seu cinema perde parte do caráter de resistência que forma, para os redatores da Cahiers, a peça central de seus filmes. Na conclusão do texto, no entanto, Pierre relativiza essa leitura, instituindo uma ambiguidade característica dos textos da Cahiers daquele período:

Sobre esse jogo duplo, não podemos insistir demais que ele seja apenas retórico, reinscrevendo o filme na nossa história - a saber, a história de uma consciência pequeno-burguesa, infeliz, separada do real, e que se refugia na arte. Não totalmente refugiada, no entanto, porque tendo sido denunciado esse refúgio na vaidade, Leone não se instala nele. (PIERRE, 1970: 55)

O próximo filme de Leone, Quando explode a vingança, ganhou resenha na Cahiers no número 238 (maio de 1972). Foi um texto curto, retornando ao padrão de ficha técnica e comentário rápido, dentro da seção "Notas críticas". Mais uma vez citando o texto de 1969 de Daney, Pierre Baudry inicia a crítica colocando uma questão pertinente e importante:

Poderíamos até recentemente questionar o lugar dos filmes de Leone no spaghetti western. Parece-me que, longe de ser sua vanguarda, esses filmes tentam mais e mais guardar uma distância em relação a essa série. Depois de ter sido um emblema e um modelo para ela (Por um punhado de dólares, Por uns dólares a mais etc.), para retomar a ideia de Daney (Cahiers $\mathrm{n}^{\circ}$ 216), os westerns de Leone são agora críticos, e não somente em relação ao cinema americano, mas também em relação ao lumpencinema italiano. (BAUDRY, 1972: 93)

Embora essa observação nos pareça fundamental, Baudry não se alonga nela (talvez por falta de espaço). Ele procura justificá-la apontando uma alteração que os filmes de Leone realizam na estrutura narrativa do gênero western: 
Longe de retomar a linearidade dos encadeamentos ficcionais do cinema de aventura e do western clássicos, os filmes de Leone, sobretudo depois de Três homens em conflito, se organizam como uma série de esquetes, uma sucessão de momentos fortes. (BAUDRY, 1972: 94)

A partir daí, Baudry envereda por uma leitura psicanalítica do filme, observando que "nada chama mais a atenção do que o desejo dos personagens". Ele destaca a construção narrativa em larga escala, detectando uma suposta alteração na forma como Leone usava flashbacks e sugerindo que esse recurso, desta vez, não seguia uma trilha que ia "do abstrato ao concreto" (o crítico refere-se, aqui, a uma técnica recorrente em Leone, que consistia em fragmentar o flashback e reapresentá-lo, aos poucos, em vários momentos do filme, a cada exibição mostrando um pouco mais da cena completa, de modo que só na última exibição conseguimos vê-la inteira e atribuir a ela um significado estável). Em Quando explode a vingança, para Baudry, os flashbacks "não explicam nada"; pelo contrário, consistem no "mistério essencial" do filme, aquilo que move a trama, transformando-a num permanente jogo de conflitos individuais, com o desejo como chave:

\footnotetext{
A organização da diferença dos desejos - entre Juan, o camponês ingênuo e ladrão lascivo, colocando constantemente o sexo em primeiro lugar, e Sean, o anjo da destruição - não estabelece relações de completude, mas sim de oposição. E é dessa oposição que surge aquilo que é colocado em jogo na revolução, que é dada num sentido ausente. (BAUDRY, 1972: 95)
}

Chama a atenção, no texto de Baudry, a mudança da abordagem teórica. A orientação marxista ainda está lá, mas percebe-se uma nova tendência à leitura psicanalítica, certamente influência da popularidade de Jacques Lacan e Christian Metz na teoria francesa de cinema dos anos 1970. Essa guinada em direção à psicanálise torna-se explícita na próxima crítica de um filme de Leone a aparecer na Cahiers du Cinéma: o texto de Michel Chion publicado no número 359 (maio de 1984, mesmo mês do lançamento do filme na França) sobre Era uma vez na América. 
ano I número |

temáticas

livres

A diferença de abordagens fica mais flagrante devido ao período de 12 anos que se passou entre as duas críticas (nesse período, Leone não lançou nenhum longa-metragem). O processo de revalorização dos filmes, contudo, continuou acontecendo. Isto fica evidente quando se observa o destaque editorial dado a Era uma vez na América. A Cahiers du Cinéma dedicou capa, editorial, entrevista e crítica ao filme, incluindo ainda um artigo escrito pelo próprio diretor. Tudo isso compôs um dossiê de 16 páginas. Era a consagração de Leone como diretor respeitado. Em duas décadas, ele havia ido de uma nota de rodapé à capa da maior revista de cinema do mundo.

Seriam os últimos textos publicados sobre Leone enquanto ele ainda vivia. Por ocasião da morte de Leone, em 1989, a Cahiers du Cinéma o homenageou publicando outro artigo escrito por ele (sobre as filmagens de Era uma vez na América), no número 422. De lá até o final de 2010, mais quatro textos apareceram nas páginas da revista, três deles registrando lançamentos em DVD de filmes de Leone e outro - um longo artigo de cinco páginas publicado no número 462, em dezembro de 1992 - traçando conexões entre Era uma vez no Oeste, a obra completa dos irmãos Joel e Ethan Coen e o então recém-lançado Os imperdoáveis (The Unforgiven, Clint Eastwood, 1992). Todos esses textos publicados após a morte de Leone foram elogiosos.

Michel Chion inicia a crítica a Era uma vez na América - que estabelece como "soberbo, ambicioso, largo, lírico, com um toque indelével do barato, do miserável, presente mesmo nos filmes mais caros de Leone, como que por solidariedade com seu país" e define como "um filme sobre o cinema" - pincelando dados biográficos e lembrando que o pai e a mãe de Leone trabalhavam na indústria cinematográfica. Ele acrescenta: "Não retomaria esses dados de psicanálise rápida se não achasse que eles esclarecem o tema central de muitos filmes realizados por ele: a busca genealógica de si dentro do universal, do autêntico na cópia, e da diferença na repetição" (CHION, 1984: 11). Essa observação é significativa. Chion interpreta o conjunto da obra de Leone como produto de um esforço (consciente ou não) autoral. 
É interessante, no texto, observar como Chion utiliza seu background como compositor de música concreta e teórico do som no audiovisual para traçar, em diversos momentos, paralelos entre o processo (praticado por Leone) de revisão dos esquemas dominantes do gênero fílmico e a ópera, que segundo Chion se utiliza do mesmo artifício, aproximando-se nesse sentido do jogo entre o familiar e o original que está no cerne da construção narrativa do cinema de gênero:

[Leone] parte do pressuposto de que todas as histórias já foram contadas, e não se preocupa com isso mais do que um compositor de ópera. Os filmes trabalham (...) com o efeito do já-visto, que é um efeito típico da ópera. Uma abertura de ópera consiste, muitas vezes, em inserir temas que só ganharão sentido na atualização de certos acontecimentos, que ressoarão como já vividos por terem sido musicalmente antecipados. (CHION, 1984: 11)

Chion também retoma e atualiza a argumentação lançada no texto de Serge Daney, embora dessa vez sem citá-lo diretamente. Para ele, a ideia de um cinema popular de resistência cultural não é mais, na década de 1980, suficiente para explicar o sucesso - e, mais significativamente, a qualidade dos filmes de Leone. Então, recorre novamente à ópera para dar o salto que Ihe permite elogiar o filme:

\footnotetext{
Do ponto de vista do ritmo, da produção e da encenação, os Estados Unidos não podem mais, atualmente, apresentar muitos filmes como esse. Não é mais suficiente, para Leone, o procedimento de criticar o cinema americano para poder existir como contestação. O cinema americano é alimentado por uma espécie de autocontestação, de uma reciclagem crítica ao infinito de seus modelos. Aqui, é a aparência que faz a diferença. É uma questão de forma, estilo e tom operístico. E em matéria de ópera, Sergio Leone está em casa. (CHION, 1984: 11)
}

Insistindo na leitura psicanalítica, Chion faz referência à construção não cronológica do enredo (procedimento importante de revisão estilística, e característica da continuidade intensificada), observando que esta é mais intrincada, sofisticada e complexa do que o jogo com os flashbacks apresentado em qualquer filme anterior de Leone. Desta feita, Chion avalia que essa estrutura 
ano I número 1

temáticas

livres não usa os momentos do passado como chaves para a resolução de um trauma obsessivo, mas permanece vazia de significado, sem levar a lugar nenhum ou seja, é pura retórica. Implicitamente, a ideia do efeito de ostentação, do "barroquismo", aparece mais uma vez. Mais importante, para Chion, é que Era uma vez na América não se traduz em bom cinema por causa da manipulação correta dos recursos estilísticos, mas porque essa manipulação, apesar de ostensiva, ainda permite brechas interpretativas que oferecem ao espectador a possibilidade de se infiltrar emocionalmente dentro da trama:

O que apaixona no filme, além do domínio da técnica, são as contradições. Entre a reconstituição histórica e o caráter mítico da trama, entre a abundância de detalhes da infância e o apagamento das figuras paternas, entre o estilo de encenação operístico e a integração de elementos instáveis e imprevisíveis como o jogo cronológico, entre muitos formidáveis atores além do genial De Niro, o grande ponto positivo é que o filme permanece aberto, suscetível ao enriquecimento aditivo. (CHION, 1984: 13)

\section{Conclusão: valor e gênero}

Analisadas em progressão, as críticas publicadas pela Cahiers do Cinéma entre 1965 e 1984 funcionam como um microcosmo consistente da trajetória da crítica na recepção dos filmes de Leone. O desprezo com que eram encarados seus primeiros westerns deu lugar, no final dos anos 1960, especialmente após a publicação da crítica de Serge Daney sobre Era uma vez no Oeste, ao respeito crítico. Gradativamente, ao longo dos anos 1970 e 1980, esse respeito aumentou e se transformou no reconhecimento à contribuição estilística de Leone ao cinema.

É importante ligar essa valorização progressiva a um processo paralelo ocorrido no campo da teoria do cinema e que certamente influenciou, ainda que indiretamente, o respeito angariado por Leone. Durante muito tempo, até meados dos anos 1970, o cinema de gênero foi colocado num polo oposto - e inferior, do ponto de vista do valor cinematográfico - em relação ao conceito de 
autoria. Essa oposição foi tratada através de diferentes gradações de ênfase, mas sua premissa essencial permaneceu estável durante décadas: filmes de gênero constituem uma categoria menos importante do que os chamados "filmes de autor", porque detêm objetivos comerciais mais imediatos.

A obra de Sergio Leone desper tou reações negativas da crítica por pertencer a um gênero cinematográfico considerado menor, mas não apenas por isso. É preciso lembrar que Leone emergiu de um ciclo de cinema popular, encarado na época como subproduto desprezível desse mesmo gênero - um subproduto sem preocupações de ordem moral ou estética, que visava apenas o lucro. Se os westerns estadunidenses eram colocados numa categoria inferior em relação ao cinema dito "de arte", os filmes do ciclo italiano não passavam, para os críticos, de imitações de segunda classe dessa categoria já inferior - ou seja, eram o subproduto de um subproduto.

Essa maneira extremamente negativa de ler o spaghetti western, que pode ser encontrada no discurso de muitos críticos dos anos 1960 e 1970, era agravada por dois fatores. Primeiro, o western lidava com a identidade cultural do povo estadunidense; os filmes eram a tentativa mais flagrante de construir uma mitologia própria para uma nação formada essencialmente por imigrantes, e que se ressentia da falta de uma história oral. Em segundo lugar, o spaghetti western era mais um dos diversos ciclos italianos de cinema popular, feito para consumo de massa. O interesse explícito dos produtores no faturamento comercial desses filmes investia frontalmente contra o conceito de arte desinteressada, que Immanuel Kant (2002) cunhou em 1790 e que constitui o alicerce fundamental da noção romântica de autoria, enraizada na cultura ocidental desde então.

Nesse ponto, convém relembrar rapidamente os fatos históricos. Na Crítica da faculdade do juízo, Kant propôs que as Belas Artes deveriam ser necessariamente desinteressadas, tanto do ponto de vista da produção quando da recepção. Para ser bela, a obra de arte teria que ser realizada com objetivos puramente estéticos, 
ano I número I

temáticas

livres

e consumida do mesmo modo. A enorme influência de Kant na filosofia do século XIX, e na igualmente influente (no século XX) teoria crítica desenvolvida pelos pesquisadores da Escola de Frankfurt (sobretudo por Theodor Adorno), garantiu que essa noção romântica de arte se entranhasse profundamente em toda a cultura ocidental. Em maior ou menor grau, esta noção está implícita em praticamente todos nós, e incide diretamente na forma como moldamos nosso gosto e nosso juízo de valor acerca do consumo estético.

Assim, não é difícil compreender os motivos pelos quais os críticos dos anos 1960 e 1970 minimizaram a importância do spaghetti western. Os filmes de Leone (e dos demais diretores do ciclo) eram recebidos com reservas mesmo antes de serem vistos, pelo simples fato de serem realizados dentro de um sistema de produção fortemente interessado no lucro. Os diretores do cinema "de arte" recebiam mais atenção e respeito porque faziam filmes cuja preocupação com as finanças era menor.

Além disso, uma teoria dos gêneros fílmicos só começou a ser efetivamente formulada, sobretudo nos Estados Unidos e na Inglaterra, entre o final dos anos 1960 e o começo dos anos 1970 (NEALE, 2000: 8). Ao longo dos anos 1970, o gênero foi tratado como um sistema, que podia ser identificado "por suas regras, componentes e funções (por sua estrutura profunda estática), ou ao contrário, pelos componentes individuais incorporados à espécie (por sua estrutura superficial dinâmica)" (SCHATZ, 1981: 18). Aos poucos, a ideia do gênero como sistema tornou-se insuficiente.

Steve Neale observou que o gênero não é exatamente um sistema, mas "um conjunto de processos de orientações, expectativas e convenções que circulam entre a indústria, o texto e o sujeito" (NEALE, 1980: 19). Essa compreensão do termo implica que gêneros não são entidades historicamente estáveis. Todo gênero incorpora novos componentes e sofre alterações com o tempo, em todos os níveis de significação. O gênero muda à medida que mudam também os três atores entre os quais circulam os seus processos de significação. 
Dessa forma, a teoria do gênero fílmico ficou marcada, após os anos 1970, pelo conceito de intertextualidade, cujo princípio fundamental é uma espécie de negação a priori da noção de autoria individual (pelo menos no sentido de Kant), pois defende que "todo e qualquer texto mantém relação com outros textos e, portanto, com um intertexto" (STAM, 2003: 225). A noção de criação intertextual pressupõe a impossibilidade da criação artística a partir do grau zero - e não apenas no cinema, mas em qualquer processo de representação ou narração. Assim, mesmo sem ter consciência, qualquer cineasta estaria construindo seus filmes a partir de certos esquemas - textos, sistemas, códigos e processos de significação - que já existiam antes dele:

Em oposição à perspectiva da Escola de Frankfurt, do gênero meramente como um sintoma de produção em série massificada, os teóricos começaram a perceber o gênero como a cristalização de um encontro negociado entre cineastas e audiência, uma forma de conciliação entre a estabilidade de uma indústria e o entusiasmo de uma arte popular. (STAM, 2003: 148).

Desta forma, a inscrição de um cineasta no rol dos autores passou a depender, ao longo dos anos 1970, da maneira como esse cineasta era capaz de trabalhar temas, códigos estilísticos e narrativos de maneira mais ou menos original, introduzindo novos elementos dentro do repertório de convenções daquele gênero específico, desde que o repertório de códigos desse mesmo gênero continuasse funcionando.

Esse raciocínio explicita o diálogo entre gênero e autoria injetado pela noção de intertextualidade, que por sua vez está conectada ao problema do estilo. A exigência que dará a qualquer cineasta o estatuto de autor é o equilíbrio entre o novo e o familiar. Ou seja, mesmo operando dentro de um gênero, o cineasta será tão mais autor quanto mais conseguir inserir elementos originais na poética do cinema, através do estilo: 
ano I número |

\section{temáticas}

livres
Os produtores de filmes populares sabem que cada filme de gênero tem de apresentar duas coisas aparentemente conflitantes: confirmar as expectativas existentes do gênero e alterá-las um pouco. É a variação da expectativa, a inovação em como um roteiro familiar é representado, que oferece ao público o prazer do reconhecimento do familiar, bem como a emoção do novo. (TURNER, 1997: 89)

Não parece ser coincidência que justamente a partir dos anos 1970, à medida que a teoria do cinema aceitava a ideia de autoria dentro do gênero, o trabalho de Sergio Leone tenha sido submetido a um processo de revalorização positiva pela crítica cinematográfica. Se é mesmo verdade que o cinema de gênero alcançou mais prestígio e popularidade ao longo dos anos 1970, como registra David Bordwell (2006: 52), é possível afirmar, amparando-se nos textos da Cahiers du Cinéma, que Sergio Leone foi um dos cineastas mais beneficiados por esse fenômeno. 


\section{Referências bibliográficas}

BAUDRY, Pierre. Il était une fois ...la révolution. Cahiers du Cinéma, Paris, n. 238, p. 93-95, maio 1972.

BONTEMPS, Jacques. Lettre d'Italie. Cahiers du Cinéma, Paris, n. 176, p. 11-12, mar. 1966a.

. Per um Pugno di Dollari. Cahiers du Cinéma, Paris, n. 177, p. 81, abr. $1966 b$.

BORDWELL, David. The Way Hollywood Tells It: Story and Style in Modern Movies. Los Angeles: University of California Press, 2006.

BRION, Patrick. Per Qualche Dollari in Più. Cahiers du Cinéma, Paris, n. 184, p. 73, nov. 1966.

CHION, Michel. Il y a un Lieu, l'Amérique. Cahiers du Cinéma, Paris, n. 359, p. 10-13, maio 1984.

COX, Alex. 10.000 Ways to Die. Londres: Kamera Books, 2009.

CRIST, Judith. Judith Crist's TV Guide for the Movies. Nova York: Popular Library, 1974.

CROWTHER, Bosley. A Fistful of Dollars. New York Times, Nova York, n. 33, 2 fev. 1967. Disponível em: <http://movies.nytimes.com/movie/review?_r=1\&res=9B03E1D D1439E53BBC4A53DFB466838C679EDE>. Acesso em: 15 de julho de 2010.

DANEY, Serge. Once Upon a Time in the West. Cahiers du Cinéma, Paris, n. 216, p. 64, out. 1969.

FRAY LING, Christopher. Spaghetti Westerns: Cowboys and Europeans from Karl May to Sergio Leone. Londres: I.B. Tauris, 1998.

GOMBRICH, E.H. Arte e ilusão: um estudo da psicologia da representação pictórica. São Paulo: Martins Fontes, 2007.

KANT, Immanuel. Crítica da faculdade do juízo. Rio de Janeiro: Forense Universitária, 2002. 
ano I número 1

temáticas

livres

MARDORE, Michel. Films de Demain. Cahiers du Cinéma, Paris, n. 166, p. 121, maio 1965.

NEALE, Steve. Genre. Londres: British Film Institute, 1980. . Hollywood and Genre. Londres: Routledge, 2000.

PIERRE, Sylvie. Coups de feu dans la Sierra Leone. Cahiers du Cinéma, Paris, n. 200, p. 124 , abr. 1968.

. Clio Veille. Cahiers du Cinéma, Paris, n. 218, p. 53-55, mar. 1970.

SADOUL, Georges. Dicionário de cineastas. Lisboa: Livros Horizonte, 1979.

SCHATZ, Thomas. Hollywood Genres: Formulas, Filmmaking and the Studio System. Nova York: Random House, 1981.

STAM, Robert. Introdução às teorias do cinema. Campinas, SP: Papirus, 2003.

TURNER, Graeme. Cinema como prática social. São Paulo: Summus, 1997.

WEISSER, Thomas. Spaghetti Westerns: A Compreensive, Ilustrated Filmography. Jefferson, NC: McFarland \& Company, 1992. 